\title{
Yemen's Cholera Epidemic Is a One Health Issue
}

\author{
Qin Xiang Ng' ${ }^{1}$, Michelle Lee Zhi Qing De Deyn ${ }^{2}$, Wayren Loke' ${ }^{1}$, Wee Song Yeo ${ }^{3}$ \\ ${ }^{1}$ Ministry of Health Holdings Pte Ltd., Singapore; ' ${ }^{2}$ epartment of Medicine, James Cook University Hospital, Middlesbrough, United Kingdom; \\ ${ }^{3}$ Mount Elizabeth Hospital, Singapore
}

Yemen has been faced with the worst cholera epidemic of modern times, with more than 1 million suspected cases and 3000 deaths at the time of writing. This problem is largely due to the longstanding civil war between pro-government forces and the Houthi armed movement, which has severely damaged already vulnerable sanitation and healthcare facilities and systems in the country. It is further compounded by a dire lack of basic amenities, chronic malnutrition, and unfavourable weather conditions. Another contributory component may be aerial transfer by cholera-infected chironomid insects. To contain the spread of cholera in Yemen, a nation-wide armistice should be negotiated, and national and local committees must be convened to coordinate efforts on the ground. Community isolation facilities with proper sanitation, reliable disposal systems, and a clean water supply should be set up to isolate and treat sick patients. The continuity of vaccination programmes should be ensured. Public health campaigns to educate local communities about good hygiene practices and nutrition are also necessary. The One Health paradigm emphasizes a multi-sectoral and transdisciplinary understanding and approach to prevent and mitigate the threat of communicable diseases. This paradigm is highly applicable to the ongoing cholera crisis in Yemen, as it demands a holistic and whole-of-society approach at the local, regional, and national levels. The key stakeholders and warring parties in Yemen must work towards a lasting ceasefire during these trying times, especially given the extra burden from the mounting severe acute respiratory syndrome coronavirus 2 (SARS-CoV-2) outbreak worldwide.

Key words: Cholera, One Health, Environment, Public health, Yemen

Yemen has been faced with the worst cholera epidemic of modern times, with more than 1.2 million suspected cases and 3000 deaths to date [1]. The cholera epidemic is of unparalleled scale and the situation is still not contained despite ongoing efforts by the World Health Organisation (WHO) and other non-governmental agencies [1]. Figure 1 below summarises the total number of suspected cholera cases in Yemen and the

Received: April 23, 2020 Accepted: May 20, 2020

Corresponding author: Qin Xiang Ng, MBBS, MPH

Ministry of Health Holdings Pte Ltd., 1 Maritime Square, Singapore

099253, Singapore

E-mail: ng.qin.xiang@u.nus.edu

This is an Open Access article distributed under the terms of the Creative Commons Attribution Non-Commercial License (https://creativecommons.org/licenses/bync/4.0/) which permits unrestricted non-commercial use, distribution, and reproduction in any medium, provided the original work is properly cited. associated case-fatality rate (CFR) from 2009 to 2019 (based on data from the WHO). Although the CFR has considerably declined, the number of suspected cholera cases remains high and in fact increased from 2018 to 2019.

Years of strife and civil war between pro-government forces and the opposing Houthi movement severely disrupted the already vulnerable water, sanitation and hygiene (WaSH) and healthcare infrastructure in Yemen, leaving more than 16 million people without basic commodities, sanitation, or healthcare. The prolonged conflict has also resulted in increased migration of people in and out of the region, and more than 2 million internally displaced individuals and refugees are forced to live in deprived, unsanitary, and squalid conditions [1]. These are hotbeds for cholera transmission, producing a clear surge in the number of suspected cases since late 2016. When sanitation and waste management systems become damaged, 


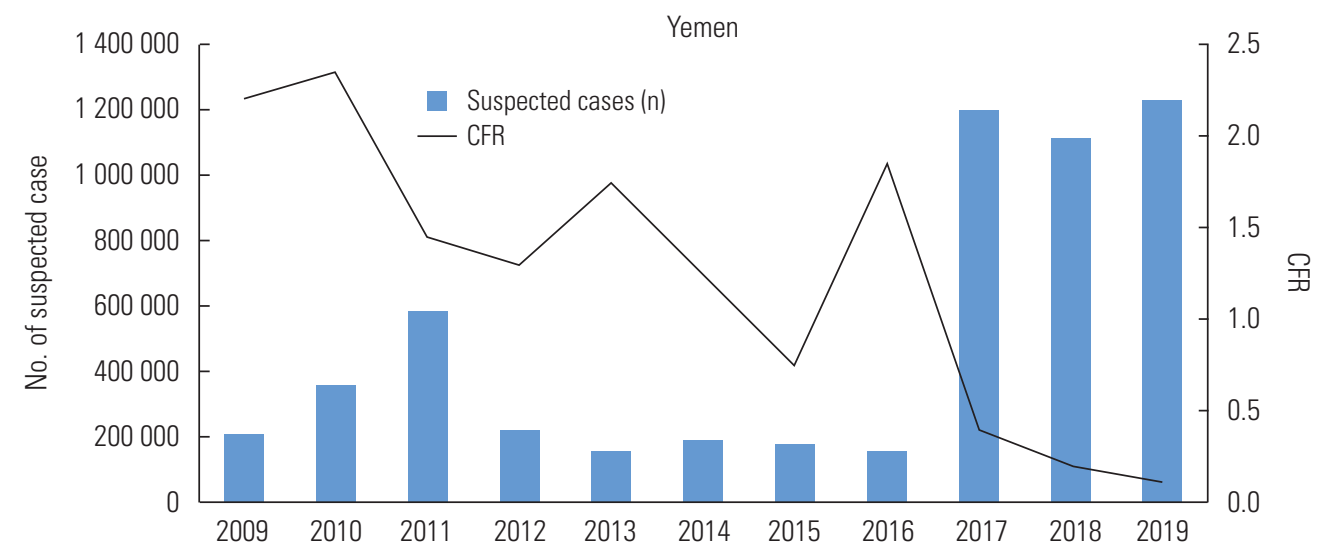

Figure 1. Total number of suspected cholera cases in Yemen and associated case-fatality rate (CFR) from 2009 to 2019.

waste materials can also easily leach into the groundwater and contaminate vegetables and surface water sources. This is especially significant, as cholera is transmitted through the faecal-oral route and as Yemen only has 10 water treatment centres (which chiefly utilize the waste stabilization pond technology), a dwindling water table, and a serious shortage of potable water [2].

A related issue is the lack of proper healthcare facilities. Due to the shortage of healthcare facilities and amenities, patients with cholera do not receive adequate treatment and may go on to infect other persons. Patients with cholera shed large amounts of highly infective organisms in their stool [3], thereby propagating a chain of infection and an epidemic situation. Without proper sanitation and waste management systems, water sources can become further contaminated, and the water scarcity problem is even worse during periods of drought or flooding.

Even before the civil war, many people in Yemen were living in poverty and suffering from chronic malnutrition [4], which lowered their immunity to cholera. There was also a shortage of oral cholera vaccinations in Yemen and many young children below the age of 5 years did not receive proper vaccinations, increasing their susceptibility to disease. Many critics have also attributed the worsening cholera epidemic to a delayed deployment of oral cholera vaccinations on the ground. A vaccination program was only initiated after nearly a million cases had occurred in the country [4].

Environmental changes also play a contributory role. Increased rainfall, flooding, and a particularly strong El Niño and winds may have further contaminated water sources in Yemen and aided the spread of cholera-contaminated flying insects (chironomids) from the Horn of Africa to Yemen [5]. Vibrio bac- teria can survive on the external surface of flies and the infected insects can release $V$. cholerae into the external environment and contaminate food [6]. Recent research has also revealed that chironomid egg masses are potential reservoirs for $V$. cholerae [6]. The warmer conditions may have also favoured algal blooms and increased $V$. cholerae reproduction and survival in the environment [7]. V. cholerae has a symbiotic relationship with many zooplankton specifies.

Some have also argued that $V$. cholerae may be transmitted via a vector, for example, through the consumption of tainted fish or shellfish [6]. This suggests that cholera might perhaps be labelled as a zoonotic disease. However, this route of transmission probably contributes a smaller role in the spread of cholera than other routes.

The One Health paradigm emphasizes a multisectoral and transdisciplinary understanding and approach to tackle infectious diseases [8]. It is highly applicable to the ongoing cholera crisis facing millions of Yemenis, as it demands a holistic and whole-of-society approach at the local, regional, and national levels. To contain the spread of cholera in Yemen, national and local committees should be convened to organise and coordinate efforts on the ground. Community isolation facilities with proper sanitation, reliable disposal systems, and a clean water supply should be set up to isolate and treat sick patients. These facilities should have enough trained healthcare personnel and the necessary equipment and medicines (including oral rehydration salts, intravenous fluids, antibiotics, and oral Vibrio vaccines) for treating cholera. All biohazard waste must be properly disposed. Ensuring adequate nutrition is also helpful for patients with cholera.

To prevent the spread of cholera, local governments and humanitarian efforts must focus on rebuilding WaSH and 
healthcare infrastructure. This may be quite difficult to achieve due to the political instability in the region; hence, it is imperative for rival parties to negotiate a nation-wide ceasefire and commit to restore normal operations. According to a 2017 report by Médecins Sans Frontières [9], Yemeni civil servants, including public sector doctors, nurses, and other healthcare workers, receive little to no remuneration, which is an untenable situation. So far, the WHO has worked with the United Nations Children's Fund to organise public vaccination campaigns, tried to restart operations of local water treatment facilities, supplied the communities with hygiene kits and water chlorination tablets, and supported 146 diarrhoea treatment centres throughout Yemen [1]. However, peace must prevail for these processes to recover and continue their smooth operations.

In terms of prevention, besides a reliable surveillance system to detect a potential outbreak in its early stages, another important preventive measure is the administration of oral cholera vaccines. Even a single dose of inactivated whole-cell oral cholera vaccine has been shown to be a safe and cost-effective way to confer protection for at least 2 years [10]. Yemen should invest in and ensure the continuity of a national vaccination programme for cholera. There may be herd immunity benefits as well.

In short, it is evident that the cholera epidemic in Yemen is a One Health problem and thus requires a collaborative, multisectoral, and transdisciplinary approach. The key stakeholders and warring parties in Yemen must work towards a lasting armistice during these trying times, especially given the extra burden from the mounting severe acute respiratory syndrome coronavirus 2 (SARS-CoV-2) outbreak worldwide.

\section{Ethics Statement}

This paper is a perspective, so it did not need ethical approval.

\section{CONFLICT OF INTEREST}

The authors have no conflicts of interest associated with the material presented in this paper.

\section{FUNDING}

None.

\section{ACKNOWLEDGEMENTS}

None.

\section{AUTHOR CONTRIBUTIONS}

Conceptualization: QXN. Data curation: QXN, MLZQDD, WL, WSY. Formal analysis: QXN, MLZQDD, WL, WSY. Funding acquisition: None. Project administration: QXN, WSY. Writing - original draft: QXN. Writing - review \& editing: QXN, MLZQDD, WL, WSY.

\section{ORCID}

Qin Xiang Ng https://orcid.org/0000-0001-8561-2513

Michelle Lee Zhi Qing De Deyn https://orcid.org/0000-00032789-4393

Wayren Loke https://orcid.org/0000-0003-4498-9773

Wee Song Yeo https://orcid.org/0000-0002-2201-2673

\section{REFERENCES}

1. World Health Organization. Yemen; 2020 [cited 2020 Apr 20]. Available from: https://www.who.int/emergencies/crises/ yem/en/.

2. Haidera M, Alhakimi SA, Noaman A, Al Kebsi A, Noaman A, Fencl $A$, et al. Water scarcity and climate change adaptation for Yemen's vulnerable communities. Local Environ 2011;16(5): 473-488.

3. Merrell DS, Butler SM, Qadri F, Dolganov NA, Alam A, Cohen $M B$, et al. Host-induced epidemic spread of the cholera bacterium. Nature 2002;417(6889):642-645.

4. Federspiel F, Ali M. The cholera outbreak in Yemen: lessons learned and way forward. BMC Public Health 2018;18(1):1338.

5. Paz S. The cholera epidemic in Yemen - how did it start? The role of El Niño conditions followed by regional winds. Environ Res 2019;176:108571.

6. Almagro-Moreno S, Taylor RK. Cholera: environmental reservoirs and impact on disease transmission. Microbiol Spectr 2013;1(2):OH-0003-2012.

7. Faruque SM, Naser IB, Islam MJ, Faruque AS, Ghosh AN, Nair $\mathrm{GB}$, et al. Seasonal epidemics of cholera inversely correlate with the prevalence of environmental cholera phages. Proc Natl Acad Sci U S A 2005;102(5):1702-1707.

8. Gebreyes WA, Dupouy-Camet J, Newport MJ, Oliveira CJ, 
Schlesinger LS, Saif YM, et al. The global one health paradigm: challenges and opportunities for tackling infectious diseases at the human, animal, and environment interface in low-resource settings. PLoS Negl Trop Dis 2014;8(11):e3257.

9. Médecins Sans Frontières. Saving lives without salaries: government health staff in Yemen [cited 2020 May 1]. Available from: https://reliefweb.int/sites/reliefweb.int/files/resources/ msf-yemen-salaries-Ir-def.pdf.

10. Qadri F, Ali M, Lynch J, Chowdhury F, Khan Al, Wierzba TF, et al. Efficacy of a single-dose regimen of inactivated whole-cell oral cholera vaccine: results from 2 years of follow-up of a randomised trial. Lancet Infect Dis 2018;18(6):666-674. 